Research Article

\title{
Corona Virus Diseases (COVID-19) and Online Class among Children in Pokhara
}

\author{
Netra Prasad Subedi \\ Lecturer, Janapriya Multiple Campus, Faculty of Management Pokhara Nepal \\ Email: netrapsdsubedi@gmail.com
}

Article History

Received 13 March 2020

Revised 19 September 2020

Accepted 22 November 2020

\begin{abstract}
The Declaration of COVID 19 as a pandemic became a turning point that shifted the paradigm of human civilization and education system. This paper aims to explore the behavioral aspects of school-level children and the situation of online education after the COVID 19 pandemic in Nepal. The study used an exploratory research design to achieve purposes. The parents having school-level children are the population for this study. And purposive sampling technique is used to collect primary data through an online system by sharing the link of the questionnaire form to parents living in urban areas, and fifty responses collected during a month. Descriptive statistical tools used for analysis purposes. The closure of schools has increased the use of mobiles phone in children. Children spent very little time in house undertakings, indooroutdoor games, singing and dancing, and playing with family members. They have observed changes in their usual behavior, parents are feeling difficulties to handle their children in a house settings. Online education is a new use for Nepalese society and school-level education. The participation of children in online education and the effectiveness is at a satisfactory level. However, electricity, accessory devices, internet facility, the interest of children, and lack of monitoring of children's education have become the major problems. The study finding suggests that parents should take care of children's education and prevent them from the unwanted effects of using the mobile phone and other undesirable behavioral changes due to the closures of schools.
\end{abstract}

Keywords: Children Behavior, COVID 19, online Education, Pandemic, school closure

(C) The Author, published by JRCC, Janapriya Multiple Campus. 


\section{Background}

Declaration of coronavirus, COVID 19, as a pandemic by WHO on March 11, 2020, became a turning point that shifted the paradigm of human civilization. It was not only a health sector's crisis but also the crises that touch every sector of human-civilization (Times, 2020).

The COVID-19 pandemic has created the largest disruption of education systems in history, affecting nearly 1.6 billion learners in more than 190 countries and all continents. Closures of schools and other learning spaces have impacted 94 percent of the world's student population, up to 99 percent in low and lower-middle income countries. The crisis is exacerbating pre-existing education disparities by reducing the opportunities for many of the most vulnerable children, youth, and adults - those living in poor or rural areas, girls, refugees, persons with disabilities and forcibly displaced persons - to continue their learning. Some 23.8 million additional children and youths (from pre-primary to tertiary) may drop out or not have access to school next year due to the pandemic's economic impact alone (United Nations, 2020).

Governments deployed measures for learning to continue through platforms, television and radio in what has been the most far-reaching experiment in the history of education. But when it comes to reopening schools, the tempo is far more uncertain. According to UNESCO data, 100 countries have not yet announced a date for schools to reopen, 65 have plans for partial or full reopening, while 32 will end the academic year online. For 890 million students, however, the school calendar has never been so undefined. When and how to reopen schools is one of the toughest and most sensitive decisions on political agendas today. Is it safe to reopen schools or is there a risk of reigniting infections? What are the consequences to children's mental health and to the social development of young children? Are students engaged in remote learning actually learning? And when the time comes, how will schools ensure students return and help learners who have fallen behind during school closures? The decision is complex because the pandemic continues to evolve, and not in linear manner (Giannini, Jenkins, \& Saavedra, 2020).

Closures of schools mean a lack of access to the resources for the children and adolescents usually have through schools. School routines are important coping mechanisms for young people with mental health issues. When schools are closed, they lose an anchor in life and their symptoms could relapse. "Going to school had been a struggle for [some children with depression] prior to the pandemic, but at least they had school routines to stick with", said Zanonia Chiu, a registered clinical psychologist working with children and adolescents 
in Hong Kong. This situation make some of them lock themselves up inside their rooms for weeks, refusing to take showers, eat, or leave their beds. For some children with depression, there will be considerable difficulties adjusting back to normal life when school resumes. Children with special education needs, such as those with autism spectrum disorder, are also at risk. They can become frustrated and short-tempered when their daily routines are disrupted, said psychiatrist Chi-Hung Au (University of Hong Kong, Hong Kong, China). He advised parents to create a schedule for their children to reduce anxiety induced by uncertainty. $\mathrm{He}$ points out that creative ways, such as online speech and social skills training, are needed to make up for the loss (Lee, 2020).

On the other hand, this crisis has stimulated innovation within the education sector. We have seen innovative approaches in support of education and training continuity: from radio and television to take-home packages. But these changes have also highlighted that the promising future of learning, and the accelerated changes in modes of delivering quality education, cannot be separated from the imperative of leaving no one behind (United Nations, 2020).

In this context education has changed dramatically, with the distinctive rise of e-learning, whereby teaching is undertaken remotely and on digital platforms. Research suggests that online learning has been shown to increase retention of information, and take less time, meaning the changes coronavirus have caused might be here to stay. While some believe that the unplanned and rapid move to online learning - with no training, insufficient bandwidth, and little preparation - will result in a poor user experience that is unconducive to sustained growth, others believe that a new hybrid model of education will emerge, with significant benefits. "I believe that the integration of information technology in education will be further accelerated and that online education will eventually become an integral component of school education,“ says Wang Tao, Vice President of Tencent Cloud and Vice President of Tencent Education (Li \& Lalani, 2020).

Recently, the continuing development of telecommunication technology has enabled the creation of a new form of education-online education (OLE). OLE provides the flexibility and efficiency of computer-assisted instruction as well as the individual attention and support of instructor-guided instruction. It brings many new opportunities and challenges to schools, instructors, and students. Traditional schools instructors, and students must prepare themselves with new tools and skills to meet the new challenges (Huang, 1997).

According World Bank we must capitalize on innovations and gather important lessons 
on the use of technology at this unprecedented scale to move to a new normal. This can constitute a turning point to use new pedagogies to tackle the learning crisis and provide more inclusive and creative learning models. Now is the time to protect education - and education budgets - from the socio-economic fallout of the pandemic (WorldBank, 2020).

However, children in low income households are less likely to study at schools that have been offering distance learning and more likely not to be able to use it. The recent Child and Family Tracker survey by UNICEF Nepal shows that more than two-thirds of schoolchildren are deprived of distance learning. Only three out of 10 children have access to television, radio and Internet-based learning platforms. Among them, only 80 percent of children use distance learning platforms for their learning activities (COVID-19: At least a third of the world's and two-thirds of Nepal's schoolchildren unable to access remote learning during school closures, new UNICEF report says, 2020, p. 5).

Nepal is also not beyond this pandemic situation. Since March 24, 2020, all the schools are in a closed condition. There is no certainty about the reopening of the schools yet.

In this very context, this paper aims to explore the condition of child behavior and online education after COVID 19.

\section{Data and Methods}

Online education is a new use in the context of school education in Nepal. The practice of online education, its impact on children, its effectiveness, and behavioral changes in children after long time closure of schools due to the COVID 19 pandemic is a new phenomenon for our society and many countries of the world as well. In this study an exploratory research design is adopted to achieve the objectives. The parents having children learning in schools and living in urban areas are the population for this study. It is because internet facilities and online education were less in implementation in rural areas during the study period. Therefore, this study has adopted convenient cum purposive sampling technique to collect primary data.

The questionnaire was prepared in Microsoft Form and shared the link through the email and Facebook messenger to more than 100 persons and also requested them to share the link to relevant persons, but only 50 responses were possible to collect in short period (i.e August 5 to September 5, 2020) of one month. A pilot survey conducted with 30 percent of respondents for its realiability and the questionnaire was revised to eliminate the confusion and difficulties inherent in the questionnaire. The collected data processed using SPSS version 20 and Microsoft Excel and descriptive statistical tools such as frequency, mean, percentage, 
ranks, and bar diagrams have been used for analysis purposes.

\section{Results and Discussion}

\section{Characteristics of Respondents}

Table 1 shows the descriptive results of the respondents' demographic characteristics. The majority of respondents are from the 34 to 54 years age group accounting for 64 percentage, 30 percent are from the 25 to 34 age group, and only 6 percent are from 15 to 24 years age group. As per the academic qualification, majority of the respondents are having master degree and above academic qualification accounting for 72 percent, followed by bachelor degree academic background. Similarly, the leading main source of earnings of the respondents are teaching $(42 \%)$, followed by the private sectors' job (22\%), and 18 percent having self-business and commerce. Likewise, 70 percent live in own house and 26 percent live in rented house.

\section{Table 1}

Demographic Characteristics of Respondents

\begin{tabular}{llll}
\hline Demographic factor & Characteristics & Frequency & Percent \\
\hline Age & 15 to 24 & 3 & 6.0 \\
& 25 to 34 & 15 & 30.0 \\
& 34 to 54 & 32 & 64.0 \\
Academic Qualification & Literate & 1 & 2.0 \\
& Basic Level & 2 & 4.0 \\
& Plus Two & 4 & 8.0 \\
& Bachelor Degree & 7 & 14.0 \\
& Master Degree and above & 36 & 72.0 \\
Main Source of Earnings & Business \& Commerce & 9 & 18.0 \\
& Teaching & 21 & 42.0 \\
& Government Service & 3 & 6.0 \\
& Private Sector Job & 11 & 22.0 \\
& Health Sector's Service & 1 & 2.0 \\
& Defense Force & 1 & 2.0 \\
& House Rent & 1 & 2.0 \\
& Agriculture & 2 & 4.0 \\
& Other & 1 & 2.0 \\
\hline
\end{tabular}




\begin{tabular}{llll}
\hline & Rented & 13 & 26.0 \\
House Type & Own & 35 & 70.0 \\
& Other & 2 & 4.0 \\
& Total & 50 & 100.0 \\
\hline
\end{tabular}

\section{Characteristics Respondents}

Table 2 shows the level of education of children and the type of schools of responding parents. Sixty percent of children study below grade 5, and 40 percent study in class 6 to 10. Similarly, 80 percent of children study in private schools, 16 percent in community or government schools, and four percent study in INGOs.

Table 2

Level of Children Education

\begin{tabular}{llll}
\hline Factor & Characteristics & Frequency & Percent \\
\hline Level of education & Below Grade 5 & 30 & 60.0 \\
School Type & Grade 6 to 10 & 20 & 40.0 \\
& Private & 40 & 80.0 \\
& Community/Govt. & 8 & 16.0 \\
& INGO & 2 & 4.0 \\
& Total & 50 & 100.0 \\
\hline
\end{tabular}

\section{Children Behavior during Lockdown}

In this survey, the behavioral aspects of children after the closure of schools due to the COVID 19 pandemic have examined by time spent by children in a day, the most preferred thing to spend time, the observation of change in normal behavior, difficulties in handling children in the house, and the impact observed on children.

\section{Time Spending Behavior of Children}

Table 3 shows the time spending by children during the closure of the schools after COVID 19. The survey data reveals that under the time spending category of more than 3 hours a day, the largest 42 percent of children spend their time on using the mobile, and no time spending found on games. Under the time spending category of 2 to 3 hours a day, the largest 28 percent of children spent time on education and the lowest four percent on house undertakings. Under the time spending category of 1 to 2 hours a day, the largest 54 percent of children spend time on education and the lowest time spend on mobile. Under the time spending category of less than one hour the largest 72 percent of children spend time on house undertakings and the 
lowest 12 percent on education. This indicates that the children spend more time on the use of the mobile, less time spend on house undertaking and moderate time on education, television, games and computer.

Table 3

Time Spending Behavior of Children

Time spending by children (\%)

Time range

Television Mobile Computer Education Games

House undertaking

\begin{tabular}{lcccccc}
\hline$<1$ hour & 26.0 & 14.0 & 50.0 & 12.0 & 42.0 & 72.0 \\
1 to 2 hours & 38.0 & 18.0 & 26.0 & 54.0 & 48.0 & 20.0 \\
2 to 3 hours & 20.0 & 26.0 & 22.0 & 28.0 & 10.0 & 4.0 \\
$>3$ hours & 16.0 & 42.0 & 2.0 & 6.0 & 0.0 & 4.0 \\
Average (hours) & 2.26 & 2.96 & 1.76 & 2.28 & 1.68 & 1.4 \\
\hline
\end{tabular}

Table 3 presents time spending behavior of children over different things after the closure of their school. The mean value of time spending over different means in a day reveals a clear picture. On average the lowest time, 1.4 hours, spend on house undertakings but very more time spend on using the mobile accounting for 2.96 hours a day, followed by 2.28 hours on education, 2.26 hours on television, 1.76 hours on the computer or laptop, and 1.68 hours on average in indoor and outdoor games.

\section{Change in Normal Behavior of Children}

The survey data relating to observation of parents regarding behavioral changes in children have presented in Table 7. Forty-six percent of parents observed little changes in the behavior of their children, 28 percent of parents observed no changes, and $26 \%$ observed change in children's behavior after the closure of the schools due to the COVID 19 pandemic.

\section{Table 4}

Behavioral Changes in Children

\begin{tabular}{lcc}
\hline & Frequency & Percent \\
\hline Yes & 13 & 26.0 \\
No & 14 & 28.0 \\
\hline
\end{tabular}




\begin{tabular}{lcc}
\hline Little & 23 & 46.0 \\
Total & 50 & 100.0 \\
\hline
\end{tabular}

\section{Effect of COVID 19 on Children}

The survey data presented in Table 8 indicates that the majority (58\%) of parents observed "negative" effects of COVID 19 on their children, 14 percent observed "very negative" impact on children, but 20 percent observed "positive" effects and eight percent parents remained unanswered.

Table 5

Effect of COVID 19 on Children

\begin{tabular}{lll}
\hline & Frequency & Percent \\
\hline Very Negative & 7 & 14.0 \\
Negative & 29 & 58.0 \\
I don't know & 4 & 8.0 \\
Positive & 10 & 20.0 \\
Total & 50 & 100.0 \\
\hline
\end{tabular}

\section{Medium of Online Class}

Table 6 shows large numbers of children (40\%) taking online education through Zoom, 18 percent through Veda Guru, 16 percent through Google Class, eight percent through other sources, and each six percent are taking online education through Messenger, Television, and MS team.

Table 6

Medium of Online Classes

\begin{tabular}{lll}
\hline & Frequency & Percent \\
\hline Messenger & 3 & 6.0 \\
Zoom & 20 & 40.0 \\
Veda Guru & 9 & 18.0 \\
MS Team & 3 & 6.0 \\
Google Class & 8 & 16.0 \\
Television & 3 & 6.0 \\
Other & 4 & 8.0 \\
Total & 50 & 100.0 \\
\hline
\end{tabular}

\section{Problem Experienced during Online Class}


Table 7 shows the ranking of problems observed by the respondents in online education. This study depicts that regularity of electricity supply is a prime problem in online education, followed by accessory devices such as a computer, laptop, mobile, and an internet facility is the third major problem. Teaching medium/media is the fourth, the interest of children in online education is fifth, and the lack of monitoring children is the sixth major problem in online education. Lack of books and learning materials, evaluation techniques, and lack of consistency in the syllabus are the least problematics things respectively in online education.

\section{Table 7}

Problem of Online Classes

\begin{tabular}{lllll}
\hline Problem & N & Sum & Mean & Rank \\
\hline Regularity of Electricity & 50 & 131.00 & 2.62 & 1 \\
Accessory Devices & 50 & 150.00 & 3.00 & 2 \\
Internet Facility & 50 & 151.00 & 3.02 & 3 \\
Teaching Media or Medium & 50 & 221.00 & 4.42 & 4 \\
Interest of Children & 50 & 229.00 & 4.58 & 5 \\
Lack of Monitoring Children & 50 & 258.00 & 5.16 & 6 \\
Lack of Books and Materials & 50 & 337.00 & 6.74 & 7 \\
Evaluation Technique & 50 & 384.00 & 7.68 & 8 \\
Lack of Consistency in Syllabus & 50 & 389.00 & 7.78 & 9 \\
\hline
\end{tabular}

Note: 1 for most significant problem and 9 for least significant problem rating scale has been used.

\section{Children Interest on Online Classes}

Table 9 shows the interest exposed by children in online classes. The survey data reveals that the majority of children interested in participating and taking online-classes accounting for 76 percent, but 16 percent are less interested, six percent are very interested, and only two percent found not interested at all.

Table 9

Children Interest on Online classes

\begin{tabular}{lcc}
\hline & Frequency & Percent \\
\hline Very Interested & 3 & 6.0 \\
Interested & 38 & 76.0 \\
Less Interest & 8 & 16.0 \\
Not Interested at all & 1 & 2.0 \\
Total & 50 & 100.0 \\
\hline
\end{tabular}




\section{Effectiveness of Online Classes}

The study about the effectiveness observed by parents of online education on their child reveals that the majority (78\%) of parents found effective. However, 10 percent observed ineffective, eight percent remained unanswered, and each two percent observed very-effective and veryineffective of online classes for their children.

Table 10

Effectiveness of Online Classes

\begin{tabular}{lll}
\hline Effectiveness & Frequency & Percent \\
\hline Very Effective & 1 & 2.0 \\
Effective & 39 & 78.0 \\
I don't know & 4 & 8.0 \\
Ineffective & 5 & 10.0 \\
Very Ineffective & 1 & 2.0 \\
Total & 50 & 100.0 \\
\hline
\end{tabular}

\section{Discussion}

Large numbers of children were found to be spending more time in the use of mobile phones and less time in education and physical activities. Physical activity keeps the body strong and healthy and can improve mental health by decreasing symptoms of depression, anxiety, pain and loneliness. Physical activity can also improve focus, school performance, sleep and energy levels. Children who participate in regular physical activity enjoy improved relationships and a more positive body image (Staff, 2020).

Majority of children found to prefer to spend more time over mobile phone and less preference on other physical and creative activities such games, drawings, playing with family members, singing and dancing, and reading and writing. These results also indicate bad habits getting more space in their mind.

The use of mobile phones and cordless phones emit radio frequency (RF) radiation. No previous generation has been exposed during childhood and adolescence to this kind of radiation. The brain is the main target organ for RF emissions from the handheld wireless phone. An evaluation of the scientific evidence on the brain tumor risk was made in May 2011 by the International Agency for Research on Cancer at World Health Organization. The scientific panel reached the conclusion that RF radiation from devices that emit nonionizing 
$\mathrm{RF}$ radiation in the frequency range $30 \mathrm{kHz}-300 \mathrm{GHz}$ is a Group 2B, that is, a "possible" human carcinogen. With respect to health implications of digital (wireless) technologies, it is of importance that neurological diseases, physiological addiction, cognition, sleep, and behavioral problems are considered in addition to cancer (Hardell, 2017)

The survey indicates that the majority of parents are feeling difficulties in handling their children in the house setting after the closure of the schools. They also found observing some changes in the usual behavior of children and have experienced negative effects of the COVID 19 on their children. Most of the schools located in the urban areas have started taking online classes for their students as well as some television channels and radios are also broadcasting virtual-classes in this period. Most of the schools are found taking online-classes through Zoom followed by Veda Guru, and Google Class. A small percentage of children are also found participating in such classes broadcasting through the Television channels. The majority of parents have found less-sufficient duration of online-classes for their children's education.

Electricity supply, accessory devices, internet facilities, teaching medium, the interest of children, and lack of monitoring have stood as the major problems for online education. Though the majority of children are found interested in the online classes and the overall effectiveness of online-class is at a satisfactory level.

\section{Conclusion}

This closure has increased the level of the use of mobile phones in children. This behavior may take the form of addiction in school children as well as the radiofrequency radiation of mobile phones may badly affect children's mental health. Children spend little time in physical and creative activites which aslo not a good symtom. Therefore, taking steps towards shifting the behavior of children from use of mobile to other things so that it enhance physical and mental health has become essential. Children have observed changes in their usual behavior, and the risk of changing behavior towards the wrong direction exit.

Schools have just started online classes in urban areas and it is a new use in Nepalese society and school-level education. The duration of the online-class is less-sufficient which seems to extend in the days to come. The participation of children in online classes and the effectiveness is at a satisfactory level. However, the regularity of electricity, accessory devices, internet facility, the interest of children on online education, and lack of monitoring of children's education have become the major problems of online education. 


\section{References}

Giannini, S., Jenkins, R., \& Saavedra, A. J. (2020, 5 13). Reopening schools: When, where and how? Retrieved from https://en.unesco.org/news/reopening-schools-when-whereand-how

Hardell, L. (2017). Effects of mobile phones on children's and adolescents' health: A commentary. Child Development, 1-4.

Huang, A. H. (1997). Challenges and opportunities of online education. Journal of Educational Technology Systems, 230-247.

Kathmandu University School of Education. (2020, April 15). Retrieved from http://soe. kusoed.edu.np/guidelines-for-online-teaching-and-learning/

Lee, J. (2020, June 1). Mental health effects of school closures during COVID-19. Retrieved from https://www.thelancet.com/journals/lanchi/article/PIIS2352-4642(20)30109-7/ fulltext\#

Li, C., \& Lalani, a. F. (2020). The COVID-19 pandemic has changed education forever. This is how. Retrieved from https://www.weforum.org/agenda/2020/04/coronavirus-educationglobal-covid19-online-digital-learning/

Staff, S. (2020). Physical activity: Benefits of exercise for health and wellbeing. Retrieved from https://www.aboutkidshealth.ca/Article?contentid=641\&language=English

Times. (2020). World Health Organization declared COVID 19 a 'Pandemic'. Here's what that means. Retrieved from https://time.com/5791661/who-coronavirus-pandemicdeclaration/

Unicef Nepal. (2020, August 28). COVID-19: At least a third of the world's and two-thirds of Nepal's schoolchildren unable to access remote learning during school closures, new UNICEF report says. Retrieved from https://www.unicef.org/nepal/press-releases/ covid-19-least-third-worlds-and-two-thirds-nepals-schoolchildren-unable-access

United Nations (2020). Policy brief : Education during COVID-19 and beyond. New York: United Nations.

World Bank. (2020, May). The COVID-19 : Shocks to education and policy responses. Retrieved from openknowledge.worldbank.org/bitstream/handle 